\title{
A Protolith Reconstruction Model (PRM) for Metabasalt: Quantitative Protolith and Mass Transfer Estimation Based on Machine-learning Approach
}

\section{Satoshi Matsuno}

Tohoku University

Masaoki Uno ( $\square$ uno@geo.kankyo.tohoku.ac.jp )

Tohoku University

Atsushi Okamoto

Tohoku University

Noriyoshi Tsuchiya

Tohoku University

\section{Research Article}

Keywords: fluid-rock interaction, Earth, including metamorphism, metasomatism, PRMs

Posted Date: May 28th, 2021

DOl: https://doi.org/10.21203/rs.3.rs-558656/v1

License: (c) (i) This work is licensed under a Creative Commons Attribution 4.0 International License.

Read Full License 
1 A protolith reconstruction model (PRM) for metabasalt: Quantitative protolith and 2 mass transfer estimation based on machine-learning approach 3

4

5

6 Satoshi Matsuno ${ }^{1}$, Masaoki Uno ${ }^{1 *}$, Atsushi Okamoto ${ }^{1}$, and Noriyoshi Tsuchiya ${ }^{1}$

7 'Graduate School of Environmental Studies, Tohoku University, 6-6-20 Aza-Aoba,

8 Aramaki, Aobaku, Sendai 980-8579, Japan

9 *e-mail: uno@geo.kankyo.tohoku.ac.jp

10

11

12

13

Submitted to the journal Scientific Reports

14 Submitted $25^{\text {th }}$ May 2021 


\section{Abstract}

Mass transfer in rocks provides a direct record of fluid-rock interaction within

17 the Earth, including metamorphism, metasomatism, and hydrothermal alteration.

18 However, mass transfer analyses are usually limited to local reaction zones where the

19 protoliths are evident in outcrops (1-100 $\mathrm{m}$ in scale), from which regional mass transfer

20 can be only loosely constrained due to uncertainty in protolith compositions. In this study,

21 we developed protolith reconstruction models (PRMs) for metabasalt based on a machine

22 learning approach. We constructed PRMs through learning multi-element correlations

23 among basalt compositional datasets, including mid-ocean ridge, ocean island, and island

24 arc basalts. The PRMs were designed to estimate trace-element compositions from inputs

25 of 2-9 selected trace elements, and basalt trace-element compositions (e.g., Rb, Ba, U, K,

$26 \mathrm{~Pb}, \mathrm{Sr}$, and rare earth elements) were estimated from only four inputs with a 27 reproducibility of $\sim 0.1 \log _{10}$ units (i.e., $\pm 25 \%$ ). Using $\mathrm{Th}, \mathrm{Nb}, \mathrm{Zr}$, and $\mathrm{Ti}$, which are 28 typically immobile during metamorphism, as input elements, the PRM was verified by 29 applying it to seafloor altered basalt with known protoliths. When suitable immobile 30 elements are incorporated, a PRM can yield unbiased and accurate mass transfer analysis 31 of any metabasalt with unknown protolith. 


\section{Background}

Chemical alteration of rocks, or mass transfer, provides direct evidence for fluidrock interactions within the Earth and represents various geochemical processes such as seafloor alteration, subduction zone metamorphism, geothermal fluid activity, and fault zone processes. Mass transfer analyses for subduction-related metamorphism reveal element transport via dehydration reactions in subducting slabs ${ }^{1-3}$ and element cycling in subduction zones ${ }^{4,5}$ that are chemically linked to arc basalt ${ }^{6,7}$. The distribution of mass transfer in a regional metamorphic belt can reveal the spatial distributions of fluid flow in the crust and mantle ${ }^{8-10}$. Mass transfer analyses in mineral-filled veins and fault zones are related to the fluid flux ${ }^{11}$, duration of fluid infiltration ${ }^{2,12,13}$, and/or degree of fault heating ${ }^{14,15}$. Hydrothermal alteration of Archean seafloor basalt is known to be linked to the chemistry of seawater ${ }^{16,17}$. Therefore, analyses of mass transfer in chemically altered rocks are essential to better understand fluid-related processes within the Earth and the evolution of surface environments.

Mass transfer analyses are generally achieved by comparing the compositions of protolith with those of metamorphosed/altered rocks. Mass transfer at the outcrop scale $(<100 \mathrm{~m})$ can be estimated by comparing compositions of altered rocks with those of adjacent unaltered host rocks ${ }^{18-20}$. For larger scales (i.e., comparisons of rocks from various metamorphic belts), mass transfer can be qualitatively evaluated by comparing chemical differences between metamorphosed rocks (i.e., metabasalt) and their likely protoliths $^{4,5}$ (i.e., mid-ocean ridge basalt or MORB). Such mass transfer analyses, which compare protolith and metamorphosed/altered rocks, have contributed to understanding material recycling in subduction zones ${ }^{4,5}$. 
rocks is unavailable, except for cases where the protoliths are evident in outcrops. As the compositional variations of likely protoliths (i.e., basalt and sediment) are generally $\operatorname{large} e^{21-24}$, it is difficult to quantitatively evaluate the amount of mass transfer for each

61 sample. Recent analyses of regional metamorphic belts have also revealed that protoliths

62 of metamorphic rocks differ in their depositional ages and/or tectonic settings among 63 different units or grades of rock $^{5,25,2627,28}$, suggesting that it is unrealistic to assume a 64 uniform protolith composition in regional metamorphic belts or alteration zones. 65 Therefore, to better understand quantitative mass transfer, estimation of protolith 66 compositions from individual samples is required. Natural observations and experiments have revealed the tendency of mass transfer to differ according to the elements, pressure, temperature, and/or fluid chemistry involved. High-field-strength elements (HFSEs) generally show little mass transfer in seafloor alteration ${ }^{29-31}$ and low solubility in typical pressure-temperature $(\mathrm{P}-\mathrm{T})$

71 conditions of metamorphism ${ }^{32-34}$, and are generally considered as "immobile" 4,5,29-31,35.

72 Other elements, such as large-ion lithophile elements (LILEs; e.g., Rb, Ba, and Sr), have 73 large mass transfer in seafloor alteration and high solubility in metamorphic fluids ${ }^{31-34}$.

74 The mobility of these elements during metamorphism has been confirmed by various 75 mass transfer analyses of mineral veins and alteration zones ${ }^{1,3,36}$. Compilations of mass transfer in various metamorphic conditions and environments have suggested that the mobility of HFSEs decreases roughly in the order of rare earth elements (REEs) $>U>$

$78 \mathrm{Nb}>\mathrm{Ti}>\mathrm{Th} \sim \mathrm{Zr}$ for high-pressure subduction zone environments ${ }^{35}$. These elements are 79 widely considered as immobile elements and are therefore used for discriminating the tectonic settings of metabasalt. The general success of discrimination diagrams ${ }^{37,38}$ 81 suggests that these immobile elements retain protolith information, meaning that it should 
82 be possible to use these elements to reconstruct protolith compositions from 83 metamorphosed/altered rocks.

84 Advances in data science have provided tools for extracting information from 85 large numbers of multidimensional data. In particular, machine learning is an effective 86 way of recognizing complex patterns in images and extracting information from 87 multidimensional table data. The recent increase in data held in geochemical 88 compositional databases (e.g., PetDB and GeoRock) has allowed machine learning to 89 become established in its application to research problems in geochemistry. For example, 90 machine learning has been successfully applied to discriminate tectonic settings of basalt 91 from chemical componsitions ${ }^{24}$, and classify metamorphic protoliths from major 92 elements $^{39}$. However, previous applications of machine-learning to geochemical data 93 have been limited mainly to classification problems and have not dealt with regression 94 problems (i.e., predicting quantitative chemistry). For quantitative mass transfer/protolith 95 analyses, a new quantitative and predictive machine-learning scheme for geochemical 96 data is needed.

97 In this study, we develop protolith reconstruction models (PRMs) that estimate 98 protolith compositions of metabasalt using machine learning. First, using a basalt whole99 rock compositional dataset, we develop empirical models that learn multi-elemental 100 correlations among the dataset and then estimate trace-element compositions of basalt 101 based on the contents of a few (two to nine) elements. The numbers and combinations of 102 input elements are optimized to precisely predict the output contents. Results show that 103 basalt trace-element contents (i.e., $\mathrm{Rb}, \mathrm{Ba}, \mathrm{U}, \mathrm{K}, \mathrm{Pb}, \mathrm{Sr}$, and REEs) can be estimated from 104 only four element contents (i.e., $\mathrm{Th}, \mathrm{Nb}, \mathrm{Zr}$, and Ti). Finally, we apply the selected four105 element PRM to seafloor altered basalt and metabasalt, and demonstrate the validity of 
the model and examples of mass transfer analyses for metamorphic rocks.

107

\section{Model description}

PRMs were developed through machine learning of a compositional dataset of

110 basalt. The empirical models were designed to estimate contents of a particular trace

111 element as an output from between two and nine HFSE contents as inputs (Fig. 1). Basalt

112 compositional data were taken from the PetDB database (https://search.earthchem.org/).

113 Trace-element contents of 16 elements (Rb, Ba, U, K, La, Ce, Pb, Sr, Nd, Y, Yb, Lu, Zr,

$114 \mathrm{Th}, \mathrm{Ti}$, and $\mathrm{Nb}$ ) from a total of 8253 basalt samples were compiled, including data for mid-ocean ridge basalt (MORB), ocean island basalt (OIB), and island arc basalt (IAB) as potential protoliths of metabasalt. The distribution of compositional data for these

117 basalts varies depending on the elements, with Th and $\mathrm{Ba}$ having relatively high 118 correlations, $\mathrm{Zr}$ and $\mathrm{Y}$ having variable correlations depending on the type of basalt, and $119 \mathrm{Nb}$ and Sr having low correlations (Fig. 1a-c). These data distributions suggest non-linear 120 and multidimensional relationships among the contents of these 16 elements. PRMs were constructed with the machine learning algorithm of the gradient 122 boosting decision tree (GBDT), with separate training/test data being used to evaluate the 123 model (Fig. 1d). The GBDT is one of several decision tree algorithms that are capable of 124 fitting complex datasets (i.e., non-linear structural data) and which perform with high accuracy ${ }^{40}$. The models were evaluated by the root mean squared error (RMSE) in log space between the estimated output and the measured data:

$$
E_{i}=\frac{1}{N} \sum_{j}^{\text {sample }} \sqrt{\left(\log _{10} y_{i, j}^{\text {estimated }}-\log _{10} y_{i, j}^{\text {test }}\right)^{2}}
$$

128 where $E_{i}$ is the RMSE for element $i, N$ is the number of samples, $y_{i, j}$ estimated is the estimated 129 content of element $i$ in sample $j$, and $y_{i, j}{ }^{\text {test }}$ is the measured content of element $i$ in sample 
132 of mass transfer reported in previous studies; LILEs are mobile during fluid activity in 133 subduction zones, contact metamorphism, and seafloor alteration, whereas HFSEs are 134 immobile during fluid activity ${ }^{29-31,33-35}$. The order of mobility of HFSEs is REEs $>U>$ $135 \mathrm{Nb}>\mathrm{Ti}>\mathrm{Th} \sim \mathrm{Zr}$, as determined from observations of natural metamorphic rocks and 136 experiments on metamorphic conditions ${ }^{35}$. For this reason, combinations of $2-9$ elements

137 from $\mathrm{Zr}$, $\mathrm{Th}, \mathrm{Ti}, \mathrm{Nb}, \mathrm{La}, \mathrm{Ce}, \mathrm{Nd}, \mathrm{Yb}$, and $\mathrm{Lu}$ were selected as input elements, and $\mathrm{Rb}, \mathrm{Ba}$, $138 \mathrm{U}, \mathrm{K}, \mathrm{La}, \mathrm{Ce}, \mathrm{Pb}, \mathrm{Sr}, \mathrm{Nd}, \mathrm{Y}, \mathrm{Yb}, \mathrm{Lu}, \mathrm{Zr}$, Th, Ti, and $\mathrm{Nb}$ were selected as output elements. 139 Elements used as output elements were excluded from input elements. For each model 140 (combinations of particular input elements and an output element), basalt compositional 141 data were chosen to ensure that there were no missing values for input and output 142 elements in the utilized dataset (typically 3000-5000 samples).

\section{Model dependence on input elements}

145 We firstly selected the numbers and combinations of input elements to estimate 146 basalt composition. Machine-learning models were constructed for each combination of 147 input and output elements (e.g., input: $\mathrm{Th}, \mathrm{Nb}$, and $\mathrm{Zr}$; output: $\mathrm{Rb}$ ). Therefore, the number 148 of possible combinations of the input elements is $2^{9}-1=511$. As each machine-learning 149 model was developed for each output element independently, 5872 machine learning models were developed in total.

Examples of estimated compositions for a specific basalt sample are shown for

152 different sets of input elements in Figure 2a, b, and c. The reproducibility of the estimation 153 is dependent largely on input elements. For example, in the case of the input elements 
154 being $\mathrm{Yb}$ and $\mathrm{Lu}$, the reproducibility (i.e., the difference between the actual and estimated 155 compositions) for each element is large (Fig. $2 \mathrm{a}$; i.e., $>1$ in $\log _{10}$ units); in contrast, when 156 the input elements are $\mathrm{Th}$ and $\mathrm{Ti}$, or $\mathrm{Nd}, \mathrm{Ti}, \mathrm{Yb}$ and $\mathrm{Lu}_{2}$ the reproducibility for each 157 element is greatly improved and is $<0.2$ in $\log _{10}$ units (Fig. $2 \mathrm{~b}$ and c). Consequently, this 158 dependence of reproducibility on input elements indicates that the numbers and 159 combinations of elements affect the estimation of composition.

160 Effects of input elements were evaluated by taking averages of RMSE scores.

161 Figure $2 \mathrm{~d}$ shows the average RMSE scores of all output elements for each combination 162 of input elements (511 cases; best model score of $\mathrm{Zr}$, Th, $\mathrm{Nb}$, La, and $\mathrm{Yb}=0.089$; worst 163 model score of $\mathrm{Lu}=0.32$ ). The top $12 \%$ of models all include $\mathrm{Th}$, and $18 \%$ of models 164 include $\mathrm{Nb}$. Figure 2e shows average RMSE scores for all of the models classed by the 165 number of input elements. For the case where the number of input elements is more than four, the averaged RMSE scores converge around 0.11 ( 0.115 for four input elements and

1670.110 for five input elements). The effect of each input element was evaluated by taking 168 the average of all of the models containing a particular element as inputs (Fig. 2f). Models 169 using $\mathrm{Th}$ and $\mathrm{Nb}$ as inputs have slightly lower average scores than the other models. These 170 results indicate that the trace-element composition of basalt can be suitably estimated 171 from only four (or five) input elements. The RMSE score of all output elements does not 172 change substantially with the combinations of input elements. The top $37 \%$ of models fall within the range of RMSE $\leq 0.11$. The three best

174 models consist of five input elements: Th, $\mathrm{Nb}, \mathrm{La}, \mathrm{Zr}$, and $\mathrm{Yb}(\mathrm{RMSE}=0.089)$; Th, $\mathrm{Nb}$, $175 \mathrm{La}, \mathrm{Nd}$, and $\mathrm{Lu}(\mathrm{RMSE}=0.091)$; and $\mathrm{Th}, \mathrm{Nb}, \mathrm{La}, \mathrm{Zr}$, and $\mathrm{Lu}(\mathrm{RMSE}=0.092)$. Among 176 the models with four input elements, the best combinations are $\mathrm{Th}, \mathrm{Nb}, \mathrm{La}$, and $\mathrm{Y}$ (RMSE $177=0.092), \mathrm{Th}, \mathrm{Nb}, \mathrm{La}$, and $\mathrm{Lu}(\mathrm{RMSE}=0.092)$, and Th, Nb, Ce, Yb $(\mathrm{RMSE}=0.093)$. The 
top $37 \%$ of models (189 combinations of input elements) have almost identical RMSE values (0.09-0.11), or reproducibilities of $\pm 0.09-0.11$ in $\log _{10}$ units, or $\pm 24 \%-28 \%$.

The performance of a particular output element improves in cases where input elements have similar incompatibility to that of the target element. For example, the RMSE of $\mathrm{Ce}$ is improved when the input combinations include $\mathrm{La}$ and $\mathrm{Nd}$ (Supplementary Fig. 1). The dependence of RMSE on input elements indicates that input elements with closer compatibility to that of the output element contain more identifying information on protolith composition. For example, the RMSE of Ce gradually improves when the input elements have closer compatibility with $\mathrm{Ce}^{41}$. As a whole, to improve the overall estimation, it is necessary to choose input elements that have a wide range of incompatibility when combined.

The constructed models for estimating basalt composition can be used to reconstruct the protolith composition of metamorphosed or altered basaltic rocks. Assuming that the contents of immobile elements in metabasalt are identical to those of its protolith, these contents can be assigned as input elemental contents of PRMs (Fig. 1d). Then, the amounts of transfer of the other elements (mobile elements during metamorphism or alteration) can be obtained by comparing their observed and predicted contents. It is noted that elements that are immobile during alteration or metamorphism may vary from case to case ${ }^{35}$; as such, users can choose PRMs with other input combinations by selecting the appropriate four to five immobile elements for the geochemical system of interest.

\section{PRM reproducibility using the example of models incorporating $\mathrm{Th}, \mathrm{Nb}, \mathrm{Zr}$, and $\mathrm{Ti}$} In the following application to metabasalt, the combination of the four elements 
of $\mathrm{Th}, \mathrm{Nb}, \mathrm{Zr}$, and $\mathrm{Ti}$ was chosen as the input of the PRM, as these elements are the most 203 immobile elements from both natural observations and experiments ${ }^{32-35}$ and have a wide 204 variety of compatibility ${ }^{41}$. The PRM was constructed by using 3000 basalt samples (i.e., 205 data containing all of the input elements and an output element) and can estimate protolith 206 compositions with an RMSE of $\sim 0.1$ (i.e., $\pm 25 \%$; Fig. 2 d).

208 of the compositional dataset for basalt. The estimated contents show largely linear 209 relationships with the raw (measured) contents in log-log space, with a slope of 1.0 (Fig.

2103 3). These results show that the PRM closely reproduces individual elements through a 211 wide range of their contents. Scatter plots of $\mathrm{La}, \mathrm{Ce}, \mathrm{Nd}, \mathrm{Y}, \mathrm{Yb}$, and $\mathrm{Lu}$ show relatively 212 small deviations from the 1:1 line and show almost no dependence on tectonic setting. In 213 comparison, distributions of $\mathrm{Rb}, \mathrm{Ba}, \mathrm{U}, \mathrm{K}, \mathrm{Pb}$, and $\mathrm{Sr}$ have relatively large dispersions. 214 In particular, dispersions of $\mathrm{Rb}$ and $\mathrm{K}$ are apparent for low contents of elements. These 215 results also affect the distribution of reproducibility of each element (Fig. S2). The 216 reproducibility of $\mathrm{Rb}, \mathrm{U}, \mathrm{K}, \mathrm{Pb}$, and $\mathrm{Sr}$ differs according to tectonic setting, with the other 217 elements showing no or only slight dependence on tectonic setting. The distributions of 218 reproducibility for MORB have a wider range than those for OIB and IAB for $\mathrm{Rb}$, and $\mathrm{U}$, 219 whereas those for IAB are slightly wider than those for MORB and/or OIB for $\mathrm{Ce}, \mathrm{Sr}$, 220 and $\mathrm{Nd}$.

One explanation for the dependence of element content on tectonic setting is the analytical detection limit. In particular, the raw data for $\mathrm{K}$ have identical values for 223 samples with low contents $\left(\leq 10^{3} \mathrm{ppm}\right)$, and the reproducibility of such data are large, 224 probably because of the detection limit of $\mathrm{K}$ in X-ray fluorescence (XRF) analyses and/or 225 the resolution of the original dataset (i.e., $\sim 0.1 \mathrm{wt} . \%$ ). An alternative explanation is 
226 seafloor alteration, for which $\mathrm{Rb}, \mathrm{Ba}, \mathrm{U}, \mathrm{K}, \mathrm{Pb}$, and $\mathrm{Sr}$ are mobile ${ }^{30,31,42}$. Some samples

227 of MORB and IAB might have already undergone mass transfer by hydrothermal 228 alteration because parts of these were collected from the ocean seafloor, with the sample 229 data being correspondingly affected. It is likely that some of the "fresh" basalts in the 230 training data have been affected by the detection limit and/or seafloor alteration, 231 contributing to enlargement of the reproducibility of models; the estimation of $\mathrm{Rb}, \mathrm{Ba}, \mathrm{U}$, $232 \mathrm{~K}$, and $\mathrm{Pb}$ can be potentially changed by removing such alteration-affected data.

233 Examples of PRM estimation for each tectonic setting are presented in Figure 4. 234 These estimations were derived by models incorporating only $\mathrm{Th}, \mathrm{Nb}, \mathrm{Zr}$, and $\mathrm{Ti}$. The 235 varied compositional patterns of different tectonic settings can be reasonably estimated 236 from these four input elements only, within a reproducibility of $\pm 25 \%$.

\section{Application to seafloor altered basalt: validation of the PRM}

To validate the PRM-reconstructed compositions, we applied the four-element

$240 \mathrm{PRM}$ incorporating $\mathrm{Th}, \mathrm{Nb}, \mathrm{Zr}$, and $\mathrm{Ti}$ to seafloor altered basalt, whose protolith 241 composition has been already estimated from fresh volcanic glass ${ }^{31}$. The reconstructed 242 protolith compositions were compared with the volcanic glass compositions identified as 243 protolith $^{31}$.

Altered-sample compositions were derived from Ocean Drilling Program (ODP)

245 Site $801^{31}$ ( http://www-odp.tamu.edu/ ). ODP Site 801 is located in $170 \mathrm{Ma}$ crust to the 246 east of Mariana Island in the Pacific plate. Altered minerals are commonly composed of 247 saponite and calcite. PRM was applied to samples 801-MORB-110-222_ALL and 801C 248 Super, which are characterized by enrichment in $\mathrm{Rb}, \mathrm{U}, \mathrm{K}$, and $\mathrm{Li}$. 
250 The PRM-based primitive-mantle-normalized protolith compositions have smooth 251 patterns, and elements with higher compatibility have higher contents ${ }^{41}$ (Fig. 5a and c).

252 These PRM-based compositions are within the range of protolith compositions estimated 253 from fresh glass. Protolith composition can be accurately reconstructed from seafloor 254 basalt.

Furthermore, mass mobility (i.e., the ratio of element content in the altered

256

257

258

259

260

261

262

263

264

265

266

267

268

269

270

271

272

273

Application to metabasalt: An example of metamorphic mass transfer analysis using a PRM

We also applied the PRM incorporating $\mathrm{Th}, \mathrm{Nb}, \mathrm{Zr}$, and Ti as inputs to an eclogite sample (Z139-6) obtained from central Zambia within the Zambezi belt, part of the PanAfrican orogenic system between the Conga and Kalahari cratons ${ }^{5}$. Peak metamorphic conditions have been estimated as 2.6-2.8 $\mathrm{GPa}$ and $630-690{ }^{\circ} \mathrm{C}^{43}$. The sample is porphyroblastic eclogite composed of omphacite, garnet, kyanite, and quartz that has replaced plagioclase. The sample shows no evidence of prograde blueschist- or amphibolite-facies metamorphism but displays evidence of direct eclogitization from gabbroic assemblages. Reaction textures and chemical analyses have revealed that this sample records prograde eclogitization and mass transfer influenced by fluid derived from 
274 the serpentinized lithospheric mantle of a subducting slab ${ }^{5}$. On the basis of comparisons 275 with empirically determined likely protolith composition, the fluid is inferred to have 276 been strongly undersaturated in light REEs (LREEs) and LILEs ${ }^{5}$. We applied the PRM to 277 sample Z139-6, which is characterized by depletion in $\mathrm{Rb}, \mathrm{Ba}, \mathrm{La}, \mathrm{Ce}, \mathrm{Sr}$, and Nd.

278 The reconstructed primitive-mantle-normalized protolith composition shows 279 that elements with higher compatibility have higher contents (Fig. 5e). Compared with its 280 protolith, the eclogite is depleted in LREEs ( $\mathrm{La}, \mathrm{Ce}$, and $\mathrm{Nd}$ ) and LILEs (Rb, Ba, and Sr), 281 with LREEs and Sr decreased by about $95 \%$, and $\mathrm{Rb}$ and $\mathrm{Ba}$ decreased by $60 \%$ and $50 \%$, 282 respectively (Fig. 5f). In addition, U, and heavy REEs (HREEs) do not show mass transfer. 283 This chemical pattern of protolith composition and element mobility is consistent with 284 the empirically estimated protolith composition and mass transfer ${ }^{5}$. These results suggest 285 that the PRM can accurately reconstruct protolith compositions from metamorphic rock 286 geochemistry.

\section{Implications of PRM-based estimates of mass transfer}

The mass transfer estimated using a PRM is an integral value between fresh 290 basalt and an altered sample. In the case where an analyzed sample has undergone 291 regional metamorphism, this value includes the mass transfer that occurred during 292 seafloor alteration, prograde metamorphism, and/or retrograde metamorphism. By 293 utilizing multi-elemental mass transfer data as well as petrological indexes such as 294 reaction extent, these complex mass transfers can be assigned to each process; a 295 comparison of PRM-based mass transfer with the degree of alteration or retrogression can reveal element transport at a particular stage of alteration or retrogression. 
298 transfer has occurred and for which the protoliths are unknown. For example, in previous 299 studies, quantitative analyses of mass transfer during metamorphism and metasomatism 300 have usually been limited to a scale of $<10 \mathrm{~m}$, where protolith homogeneity can be 301 assumed ${ }^{1,3}$. Provided that the distribution of data is retained within training data (i.e., 302 mafic rocks with either a MORB, OIB, or IAB origin), the mass transfer can be estimated 303 by a PRM for individual samples independently, and thus their spatial variation provides 304 important information for constraining the regional-scale (i.e., $>1 \mathrm{~km}$ ) mass transfer, even 305 if the protolith compositions are heterogeneous. The PRMs utilized in this study allow 306 analysis of various types of sample that have undergone mass transfer (e.g., seafloor 307 altered basalt or contact metamorphic rock) with incorporation of appropriate immobile 308 elements. Immobile elements used for PRM inputs can be selected from 511 combinations 309 of 9 elements according to petrological and geochemical observations.

310 In cases where protoliths are unknown, conventional mass transfer analyses have 311 relied on the experience and intuition of the trained geochemist, including empirical 312 fitting or assuming a suitably representative basalt as the protolith, such as MORB or OIB. 313 "Anomalies" on normalized multi-elemental variation diagrams (i.e., spidergrams) are 314 considered to show mobile elements. In contrast, the data-driven approach of the present 315 study is applicable to investigating heterogeneities of protolith compositions and provides 316 a less biased and more accurate estimation of metamorphic mass transfer for independent 317 samples. Such a data-driven method is suitable for quantitative mass transfer analysis, 318 especially in cases where protoliths are unknown and/or when there is a need to analyze 319 mass transfer from a compiled dataset with samples from various tectonic origins.

\section{Conclusion}


323 metabasalt, using machine-learning with large numbers of basalt compositional data. The

324 best PRMs can estimate trace-element contents of basalt with an error of around \pm 0.1 in

$325 \log _{10}$ units or $\pm 25 \%$ incorporating only four or five input element contents. Using 326 immobile elements as input elements, a four-element PRM was used to estimate protolith

327 compositions of metabasalt. Application to seafloor altered basalt and eclogite verified

328 the accuracy of protolith reconstruction within reasonable uncertainty of the estimation

329 (0.1 in $\log _{10}$ units or $\left.25 \%\right)$. This machine-learning-based method enabled an analysis of 330 mass transfer of metabasalt with unknown protolith and can be applied to regional 331 metamorphic belts or alteration zones where the protolith is heterogeneous. 
PRMs were constructed using the machine learning algorithm of the gradient

338 boosting decision tree, specifically, the LightGBM algorithm. To improve empirical model reproducibility, hyperparameters of LightGBM were automatically tuned through Bayesian optimization by using a partial training dataset. Partial training datasets for

341 hyperparameter tuning were prepared by K-fold cross validation, which enabled us to use

342 all training data for constructing the PRMs. Details of the machine-learning calibrations 343 for PRMs are described below.

\section{Gradient boosting decision tree (LightGBM)}

Gradient boosting decision tree (GBDT) is a supervised machine-learning

347 method from which prediction models can be constructed from multidimensional data 348 and used to solve classification and regression problems ${ }^{44}$. In the field of geochemistry, 349 this machine-learning method has been applied to extract information, discriminate 350 classes, and predict values; for example, to discriminate and extract characteristics from 351 a volcanic rock dataset of eight different tectonic settings ${ }^{24}$, classify metamorphic 352 protolith(s) from the major element contents of a rock $^{39}$, and complement geochemical 353 mapping for improvement of accuracy and interpretation ${ }^{45}$. Both random forests and GBDT have been proposed as explainable models with 355 high accuracy. GBDT is an ensemble method that combines multiple decision trees to build a powerful model. In the GBDT method, decision trees are built one after another

357 in such a way that the next decision tree corrects the errors of the previous one ${ }^{40}$. The 358 development of GDBT has allowed various algorithms such as Xgboost $^{46}$ and Catboost ${ }^{47}$ 359 to be proposed, of which LightGBM is an algorithm with fast calculation time and high 
accuracy $^{48}$. For this reason, LightGBM was used as the machine-learning algorithm and

361 for constructing models to predict element contents.

\section{Tuning hyperparameters}

LightGBM is a decision-tree-based nonparametric model. A nonparametric model has higher degrees of freedom compared with a linear model because of the fewer assumptions needed regarding the training data. However, the flexibility of a decision tree model makes it easier to overfit the training data. To solve this overfitting problem, each model has hyperparameters to restrict the degrees of freedom. Given that appropriate values can be assigned depending on the structure and number of dimensions of datasets, the hyperparameters need to be selected.

372 them automatically for the dataset. Bayesian optimization is a method that uses the

373 framework of Bayesian probability to select the next parameter to be explored based on

374 the history of previously calculated parameters ${ }^{49}$. In this study, Optuna was used as the 375 optimization software ${ }^{50}$, with a part of the data being used as the validation for 376 hyperparameter tuning by Bayesian optimization. The number of hyperparameter 377 searches was set to 50. The tuned hyperparameters were as follows: num_leaves: the maximum number of leaves in one tree; max_depth: limit the depth for the tree model. This can be used to deal with overfitting; and min_data_in_leaf: the minimum number of data in one leaf.

382 These three parameters are specified in the official LightGBM documentation as the first 383 to be tuned. The other parameters are set with default values. 
Model construction

\section{K-fold cross-validation}

Data with no missing values in the input and output elements were extracted

388 from the basalt compositional dataset and divided into training or test data. One-fifth of

389 the data were used as test data to evaluate the accuracy of model, and the remaining data

390 were used as training data to construct machine-learning models. hyperparameters and to prevent a reduction in the number of available data (Fig. S3). The training data are randomly split into $\mathrm{K}$ distinct subsets. $\mathrm{K}-1$ subsets are assigned for training the model, and the other subset is used for evaluating the hyperparameters (i.e., validation data). By changing the subsets used for training and validation, the model is evaluated $\mathrm{K}$ times (i.e., $\mathrm{K}$ folds) ${ }^{40}$. The average RMSE obtained from all folds is used for hyperparameter tuning by Bayesian optimization. In this study, we constructed a 4-fold cross validation. The reproducibility of the model was evaluated by using the test data 399 (which are independent from the training and validation data used for hyperparameter 400 tuning).

Preprocessing of each set of compositional data and Bayesian optimization

To improve the estimation error, input variables are transformed to ratios and 404 products, along with dimensional compression, with a search for the best data 405 representation (i.e., feature engineering). Feature engineering is a common technique for 406 constructing machine-learning $\operatorname{model}^{40}$. In this study, data were transformed as ratios 407 and products of contents between two arbitrary elements, and scores of Principal 
408 Component Analysis (PCA) and Independent Component Analysis (ICA) were calculated 409 from log-transformed datasets for the training data of each fold. The validation and test 410 data of each fold were also transformed using the same procedures, and their PCA and 411 ICA scores were calculated by projecting the validation/test data onto the PCA/ICA 412 eigenvectors of the training data. All of the measured content data, products, ratios, and $413 \mathrm{PCA} / \mathrm{ICA}$ scores were used as preprocessed data for training and estimation of the 414 machine learning models.

415 Preprocessed training data were used to construct machine-learning models, and 416 we applied the models to preprocessed validation data to evaluate the reproducibility by 417 RMSE (Fig. S3). Based on the averages of the obtained RMSE, Bayesian optimization 418 software (Optuna) performed to tune the model's hyperparameters. We repeated model 419 construction and evaluation 50 times to find the appropriate hyperparameters for each set 420 of compositional data. 


\section{References}

1. Taetz, S., John, T., Bröcker, M. \& Spandler, C. Fluid-rock interaction and evolution of a high-pressure/low-temperature vein system in eclogite from New Caledonia: insights into intraslab fluid flow processes. Contrib. to Mineral. Petrol. 171, (2016).

2. Taetz, S., John, T., Bröcker, M., Spandler, C. \& Stracke, A. Fast intraslab fluidflow events linked to pulses of high pore fluid pressure at the subducted plate interface. Earth Planet. Sci. Lett. 482, 33-43 (2018).

3. Beinlich, A., Klemd, R., John, T. \& Gao, J. Trace-element mobilization during Ca-metasomatism along a major fluid conduit: Eclogitization of blueschist as a consequence of fluid-rock interaction. Geochim. Cosmochim. Acta 74, 18921922 (2010).

4. Bebout, G. E. Metamorphic chemical geodynamics of subduction zones. Earth Planet. Sci. Lett. 260, 373-393 (2007).

5. John, T., Scherer, E. E., Haase, K. \& Schenk, V. Trace element fractionation during fluid-induced eclogitization in a subducting slab: Trace element and LuHf-Sm-Nd isotope systematics. Earth Planet. Sci. Lett. 227, 441-456 (2004).

6. Pearce, J. A., Stern, R. J., Bloomer, S. H. \& Fryer, P. Geochemical mapping of the Mariana arc-basin system: Implications for the nature and distribution of subduction components. Geochemistry, Geophys. Geosystems 6, (2005).

7. C. J. Hawkesworth;, Gallagher;, K., Hergt; J. M. \& McDermott; F. P. Mantle and Slab Contributions in ARC Magmas. Earth 175-204 (1993).

8. Ferry, J. M. Regional metamorphism of the waits river formation, Eastern Vermont: Delineation of a new type of giant metamorphic hydrothermal system. J. Petrol. 33, 45-94 (1992).

9. Ague, J. J. Mass transfer during Barrovian metamorphism of pelites, southcentral Connecticut. I: evidence for changes in composition and volume. Am. J. Sci. 294, 989-1057 (1994).

10. Masters, R. L. \& Ague, J. J. Regional-scale fluid flow and element mobility in Barrow's metamorphic zones, Stonehaven, Scotland. Contrib. to Mineral. Petrol. 150, 1-18 (2005).

11. Penniston-Dorland, S. C. \& Ferry, J. M. Development of spatial variations in reaction progress during regional metamorphism of micaceous carbonate rocks, northern New England. Am. J. Sci. 306, 475-524 (2006).

12. John, T. et al. Volcanic arcs fed by rapid pulsed fluid flow through subducting slabs. Nat. Geosci. 5, 489-492 (2012).

13. Mindaleva, D. et al. Rapid fluid infiltration and permeability enhancement during 
middle-lower crustal fracturing: Evidence from amphibolite-granulite-facies fluid-rock reaction zones, Sør Rondane Mountains, East Antarctica. Lithos 372373, 105521 (2020).

14. Ishikawa, T. et al. Coseismic fluid-rock interactions at high temperatures in the Chelungpu fault. Nat. Geosci. 1, 679-683 (2008).

15. Tanikawa, W. et al. Transport properties and dynamic processes in a fault zone from samples recovered from TCDP Hole B of the Taiwan Chelungpu Fault Drilling Project. Geochemistry, Geophys. Geosystems 10, 1-18 (2009).

16. Kitajima, K., Maruyama, S., Utsunomiya, S. \& Liou, J. G. Seafloor hydrothermal alteration at an Archaean mid-ocean ridge. J. Metamorph. Geol. 19, 583-599 (2001).

17. Shibuya, T. et al. Decrease of seawater $\mathrm{CO} 2$ concentration in the Late Archean: An implication from 2.6Ga seafloor hydrothermal alteration. Precambrian Res. 236, 59-64 (2013).

18. Grant, J. A. The isocon diagram-a simple solution to Gresens' equation for metasomatic alteration. Econ. Geol. 81, 1976-1982 (1986).

19. Grant, J. A. Isocon analysis: A brief review of the method and applications. Phys. Chem. Earth 30, 997-1004 (2005).

20. Kuwatani, T. et al. Sparse isocon analysis: A data-driven approach for material transfer estimation. Chem. Geol. 532, 119345 (2020).

21. Moss, B. E., Haskin, L. A., Dymek, R. F. \& Shaw, D. M. Redetermination and reevaluation of compositional variations in metamorphosed sediments of the Littleton Formation, New Hampshire. Am. J. Sci. 295, 988-1019 (1995).

22. Moss, B. E., Haskin, L. A. \& Dymek, R. F. Compositional variations in metamorphosed sediments of the Littleton Formation, New Hampshire, and the Carrabassett Formation, Maine, at sub-hand specimen, outcrop, and regional scales. Am. J. Sci. 296, 473-505 (1996).

23. Plank, T. \& Langmuir, C. H. The chemical composition of subducting sediment and its consequences for the crust and mantle. Chem. Geol. 145, 325-394 (1998).

24. Ueki, K., Hino, H. \& Kuwatani, T. Geochemical discrimination and characteristics of magmatic tectonic settings: A machine-learning-based approach. Geochemistry, Geophys. Geosystems 19, 1327-1347 (2018).

25. Uno, M. et al. Elemental transport upon hydration of basic schists during regional metamorphism: Geochemical evidence from the Sanbagawa metamorphic belt, Japan. Geochem. J. 48, 29-49 (2014).

26. Spandler, C., Hermann, J., Arculus, R. \& Mavrogenes, J. Geochemical heterogeneity and element mobility in deeply subducted oceanic crust; insights from high-pressure mafic rocks from New Caledonia. Chem. Geol. 206, 21-42 
(2004).

27. Aoki, K. et al. U-Pb zircon dating of the Sanbagawa metamorphic rocks in the Besshi-Asemi-gawa region, central Shikoku, Japan, and tectono-stratigraphic consequences. J. Geol. Soc. Japan 125, 183-194 (2019).

28. Cluzel, D., Aitchison, J. C. \& Picard, C. Tectonic accretion and underplating mafic terranes in the late Eocene intraoceanic fore-arc of New Caledonia (Southwest Pacific): Geodynamic implications. Tectonophysics 340, 23-59 (2001).

29. Alt, J. C. et al. Hydrothermal Alteration of a Section of Upper Oceanic Crust in the Eastern Equatorial Pacific: A Synthesis of Results from Site 504 (DSDP Legs 69, 70, and 83, and ODP Legs 111, 137, 140, and 148). Proc. Ocean Drill. Program, 148 Sci. Results 148, (1996).

30. Staudigel, H., Plank, T., White, B. \& Schmincke, H. U. Geochemical fluxes during seafloor alteration of the basaltic upper oceanic crust: DSDP sites 417 and 418. in Geophysical Monograph Series vol. 96 19-38 (1996).

31. Kelley, K. A., Plank, T., Ludden, J. \& Staudigel, H. Composition of altered oceanic crust at ODP Sites 801 and 1149. Geochemistry, Geophys. Geosystems 4, (2003).

32. Kessel, R., Schmidt, M. W., Ulmer, P. \& Pettke, T. Trace element signature of subduction-zone fluids, melts and supercritical liquids at 120-180 km depth. Nature 437, 724-727 (2005).

33. Tsay, A., Zajacz, Z. \& Sanchez-valle, C. Efficient mobilization and fractionation of rare-earth elements by aqueous fluids upon slab dehydration. Earth Planet. Sci. Lett. 398, 101-112 (2014).

34. Tsay, A., Zajacz, Z., Ulmer, P. \& Sanchez-Valle, C. Mobility of major and trace elements in the eclogite-fluid system and element fluxes upon slab dehydration. Geochim. Cosmochim. Acta 198, 70-91 (2017).

35. Ague, J. J. Element mobility during regional metamorphism in crustal and subduction zone environments with a focus on the rare earth elements (REE). Am. Mineral. 102, 1796-1821 (2017).

36. Ague, J. J. Extreme channelization of fluid and the problem of element mobility during Barrovian metamorphism. Am. Mineral. 96, 333-352 (2011).

37. Pearce, J. A. \& Cann, J. R. Tectonic setting of basic volcanic rocks determined using trace element analyses. Earth Planet. Sci. Lett. 19, 290-300 (1973).

38. Hollocher, K., Robinson, P., Walsh, E. \& Roberts, D. Geochemistry of amphibolite-facies volcanics and gabbros of the støren nappe in extensions west and southwest of Trondheim, Western Gneiss Region, Norway: A key to correlations and paleotectonic settings. Am. J. Sci. 312, 357-416 (2012). 
39. Hasterok, D., Gard, M., Bishop, C. M. B. \& Kelsey, D. Chemical identification of metamorphic protoliths using machine learning methods. Comput. Geosci. 132, 56-68 (2019).

40. Géron, A. Hands-On Machine Learning with Scikit-Learn and TensorFlow Concepts, Tools, and Techniques to Build Intelligent Systems. (O’Reilly Media, Inc., 2011).

41. Sun, S. S. \& McDonough, W. F. Chemical and isotopic systematics of oceanic basalts: Implications for mantle composition and processes. Geol. Soc. Spec. Publ. 42, 313-345 (1989).

42. Alt, J. C. \& Teagle, D. A. H. The uptake of carbon during alteration of ocean crust. Geochim. Cosmochim. Acta 63, 1527-1535 (1999).

43. John, T. \& Schenk, V. Partial eclogitisation of gabbroic rocks in a late Precambrian subduction zone (Zambia): Prograde metamorphism triggered by fluid infiltration. Contrib. to Mineral. Petrol. 146, 174-191 (2003).

44. Loh, W. Y. Classification and regression trees. Wiley Interdiscip. Rev. Data Min. Knowl. Discov. 1, 14-23 (2011).

45. Kirkwood, C., Cave, M., Beamish, D., Grebby, S. \& Ferreira, A. A machine learning approach to geochemical mapping. J. Geochemical Explor. 167, 49-61 (2016).

46. Chen, T. \& Guestrin, C. XGBoost: A scalable tree boosting system. Proc. ACM SIGKDD Int. Conf. Knowl. Discov. Data Min. 13-17-Augu, 785-794 (2016).

47. Prokhorenkova, L., Gusev, G., Vorobev, A., Dorogush, A. V. \& Gulin, A. Catboost: Unbiased boosting with categorical features. Adv. Neural Inf. Process. Syst. 2018-Decem, 6638-6648 (2018).

48. Ke, G. et al. LightGBM: A highly efficient gradient boosting decision tree. $A d v$. Neural Inf. Process. Syst. 2017-Decem, 3147-3155 (2017).

49. Snoek, J., Larochelle, H. \& Adams, R. P. Practical Bayesian optimization of machine learning algorithms. Adv. Neural Inf. Process. Syst. 4, 2951-2959 (2012).

50. Akiba, T., Sano, S., Yanase, T., Ohta, T. \& Koyama, M. Optuna: A nextgeneration hyperparameter optimization framework. arXiv 2623-2631 (2019).

51. Daisuke, K., Ryuji, S., Keisuke, H. \& Yuji, H. Data analysis techniques to win Kaggle. doi:4297108437. 


\section{Acknowledgments}

571 This study was financially supported in part by JSPS KAKENHI grants 18K13628

572 awarded to M.U. S.M., M.U., and A.O. were partly funded by Joint Usage/Research

573 Center programs (ERI JURP) 2015-B-04, 2018-B-01, and 2021-B-01 of the Earthquake

574 Research Institute, University of Tokyo, Japan. We thank the members of the ERI JURP

575 for constructive discussions.

576

\section{Author contributions}

578 S.M. designed and coded machine-learning algorithms. M.U. designed the research 579 strategy. A.O. and N.T. critically discussed the research strategy and outcomes. All of the 580 authors discussed the results and commented on the manuscript. All authors read and 581 approved the final manuscript.

582

\section{Competing of interests}

584 The authors declare that they have no competing interests.

585

586 Additional Information

587 Corresponding author

588 Masaoki UNO

589 Graduate School of Environmental Studies, Tohoku University, Sendai 980-8579, Japan

590 TEL: +81-22-795-6336

591 FAX: +81-22-795-6336

592 E-mail: uno@geo.kankyo.tohoku.ac.jp

593 

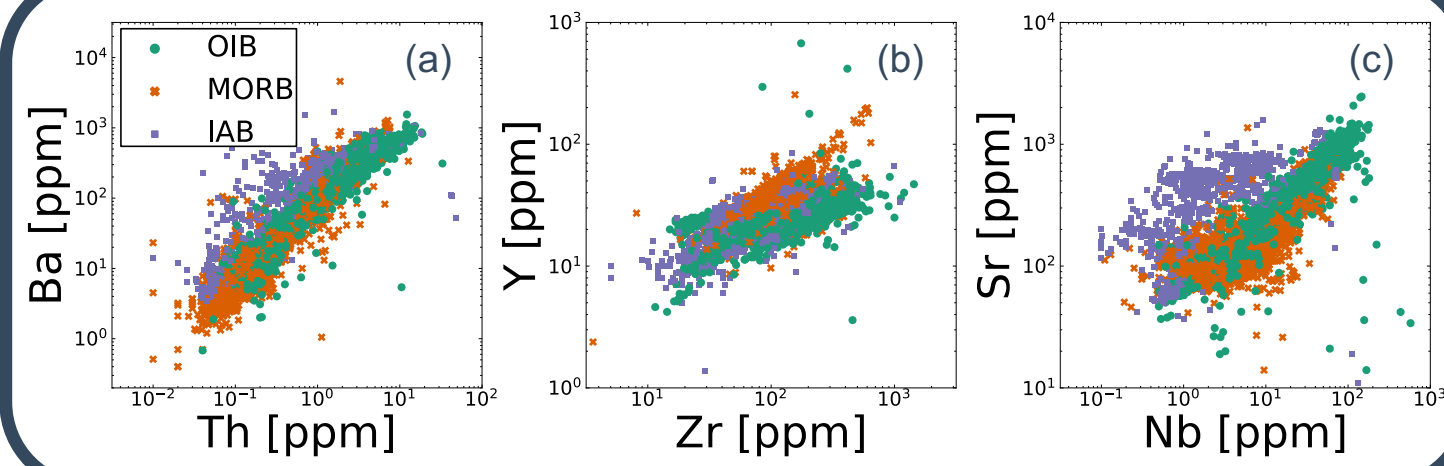

(d)

Machine Learning

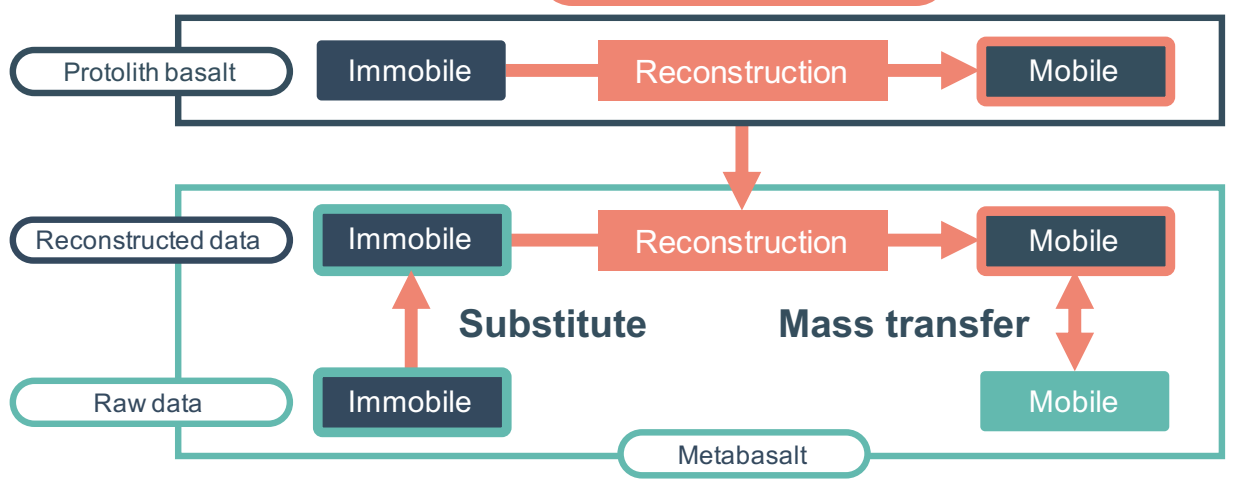

598 Figure 1. Distribution of the compositional dataset used in this study (compiled from the 599 geochemical database at https://search.earthchem.org/). (a) Th and Ba, (b) Zr and Y, and 600 (c) $\mathrm{Nb}$ and $\mathrm{Sr}$. (d) Schematic overview of protolith reconstruction models (PRMs). 601 Empirical models were calibrated by the protolith (basalt) compositional dataset and 602 applied to metabasalt compositions. Assuming that the contents of immobile elements in 603 metabasalt are identical to those in protolith basalt, these contents can be assigned as 604 inputs and used to obtain protolith compositions. 

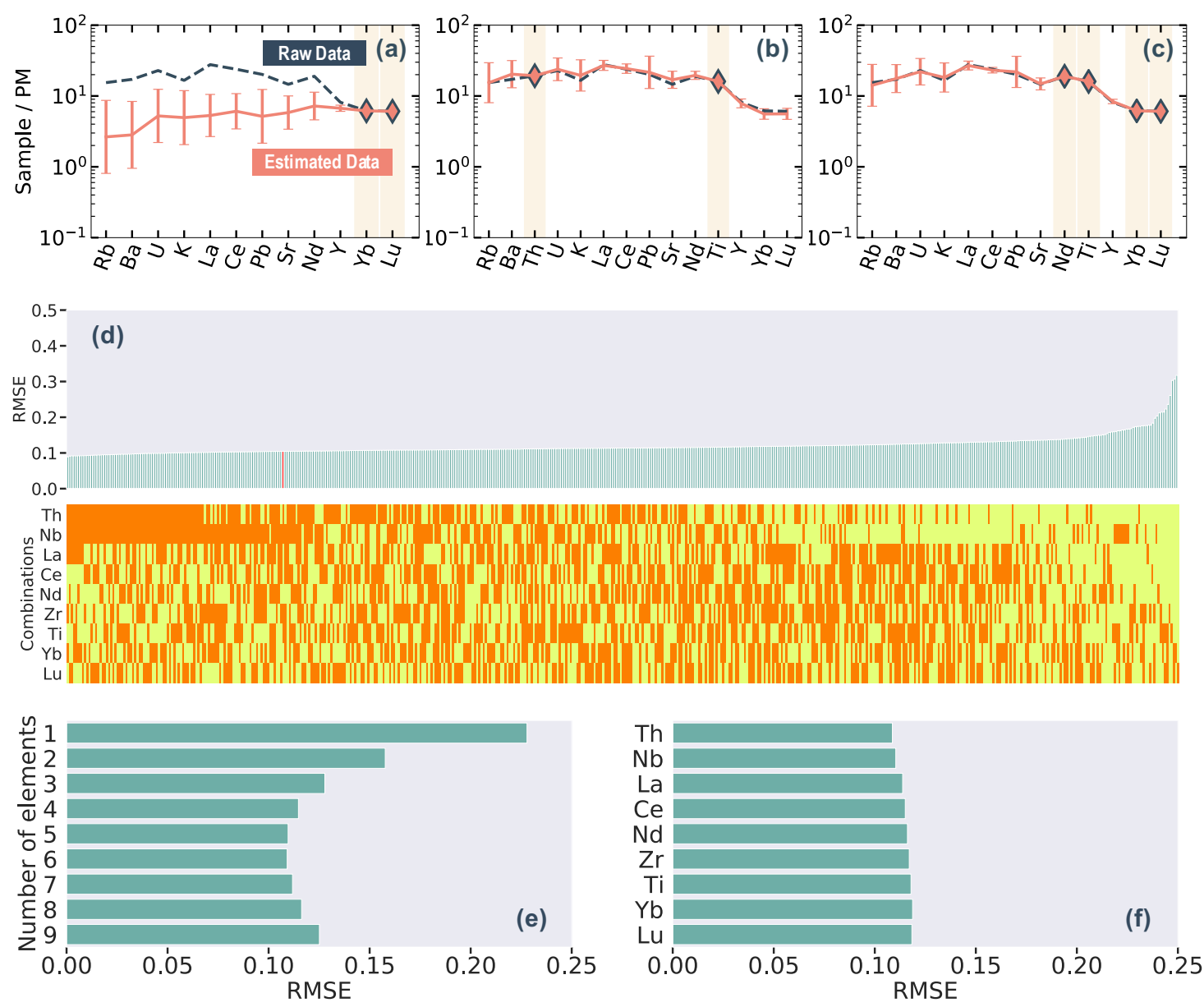

606 Figure 2. (a-c) Estimated primitive-mantle-normalized contents of basalt. Pink diamonds

607 indicate the input contents. Predicted data were obtained from the input contents of (a)

$608 \mathrm{Yb}$ and $\mathrm{Lu}$; (b) Th and Ti; and (c) $\mathrm{Nd}, \mathrm{Ti}, \mathrm{Yb}$, and $\mathrm{Lu}$. Raw basalt compositional data are 609 shown as a dashed dark-blue line, and estimated basalt compositional data are shown as 610 a pink line. Compositions of the primitive mantle are from Sun and McDonough (1989).

611 (d) Average RMSE scores of all output elements for each combination of input elements

612 (511 cases), and combinations of input elements for each model shown in below. In the 613 upper plot, the red line indicates the input combination of $\mathrm{Th}, \mathrm{Nb}, \mathrm{Zr}$, and $\mathrm{Ti}$. In the lower 614 plot, the orange elements are used in combinations, and yellow elements are not used. (e) 615 Average RMSE scores for all of the models using a particular number of input elements. 616 (f) Average of all of the models containing a particular element as an input. 

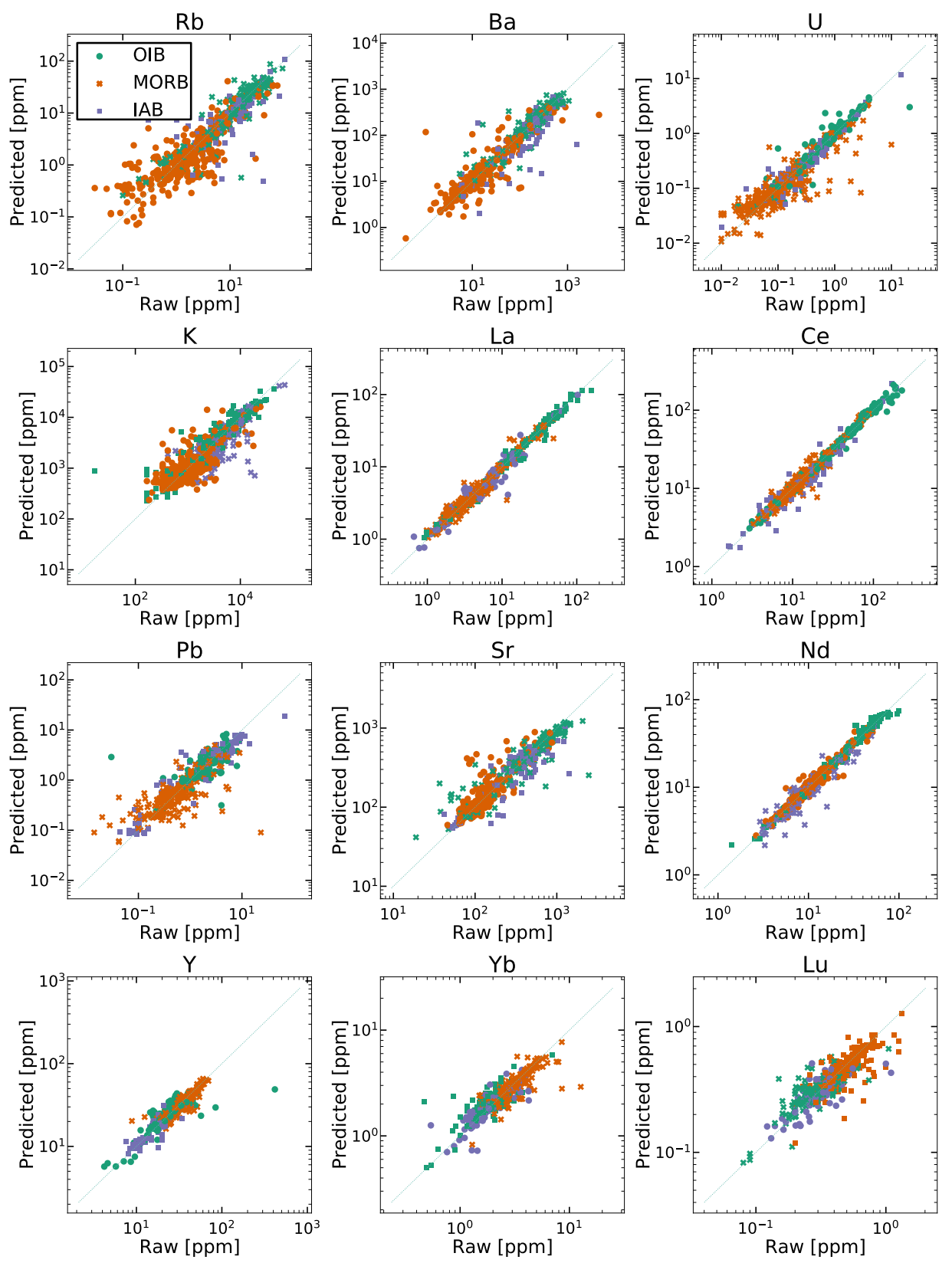

619 Figure 3. Scatter plots of predicted contents versus raw (measured) contents with the final

620 PRM using Th, Nb, Zr, and Ti as input elements. The PRM was applied to test data of the

621 basalt dataset, which covers three different tectonic settings (mid-ocean ridge basalt,

622 ocean island basalt, and island arc basalt). 

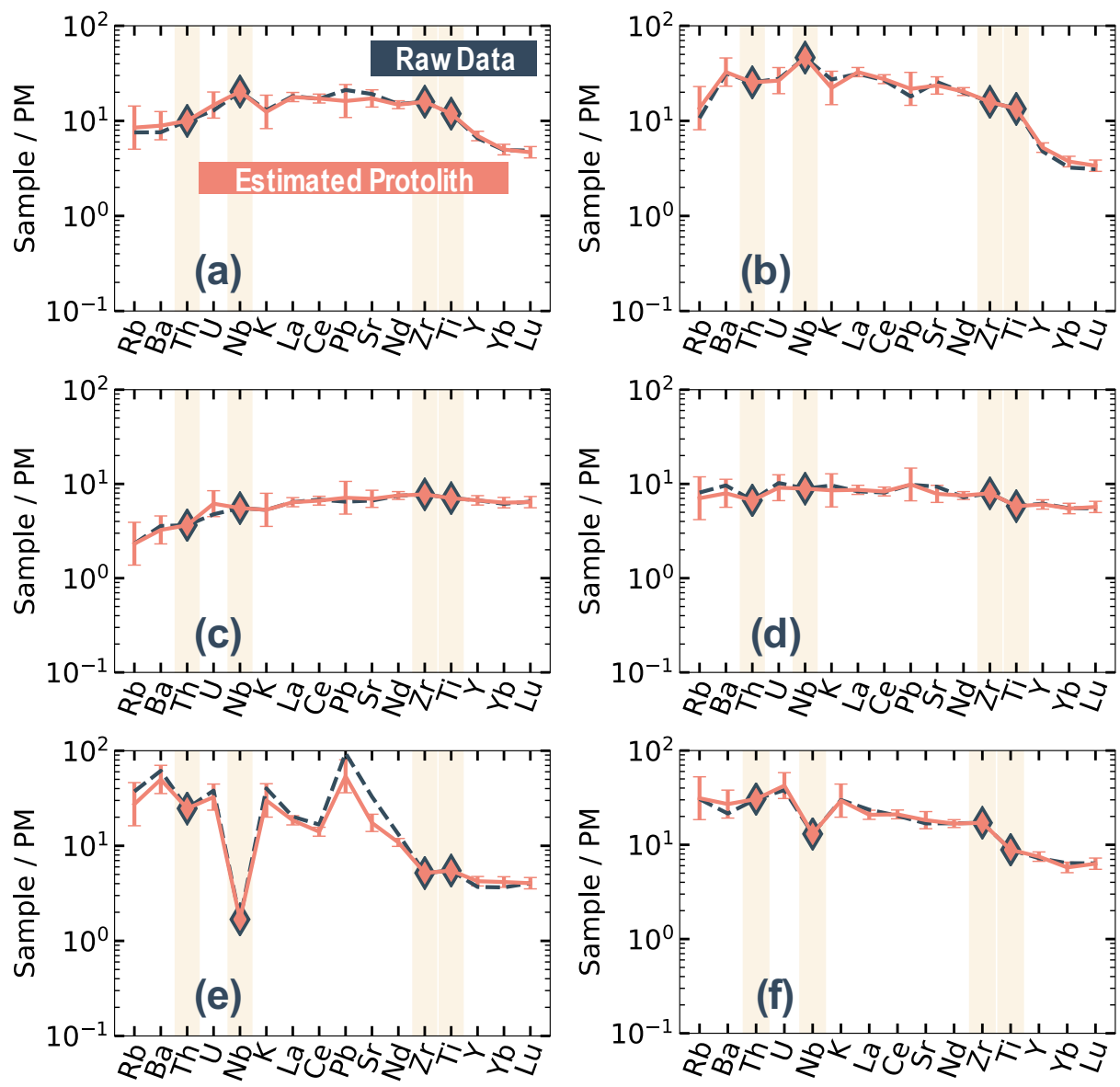

625 Figure 4. Primitive-mantle-normalized contents of estimated basalt using the four-

626 element $\mathrm{PRM}$ with $\mathrm{Th}, \mathrm{Nb}, \mathrm{Zr}$, and $\mathrm{Ti}$ as input elements. Samples for each plot are

627 examples from (a, b) OIB, (c, d) MORB, and (e, f) IAB. Diamonds indicate input data.

628 Raw basalt compositional data are shown as a dashed dark-blue line, and estimated basalt

629 compositional data are shown as a pink line. Compositions of the primitive mantle are 630 from Sun and McDonough (1989). 

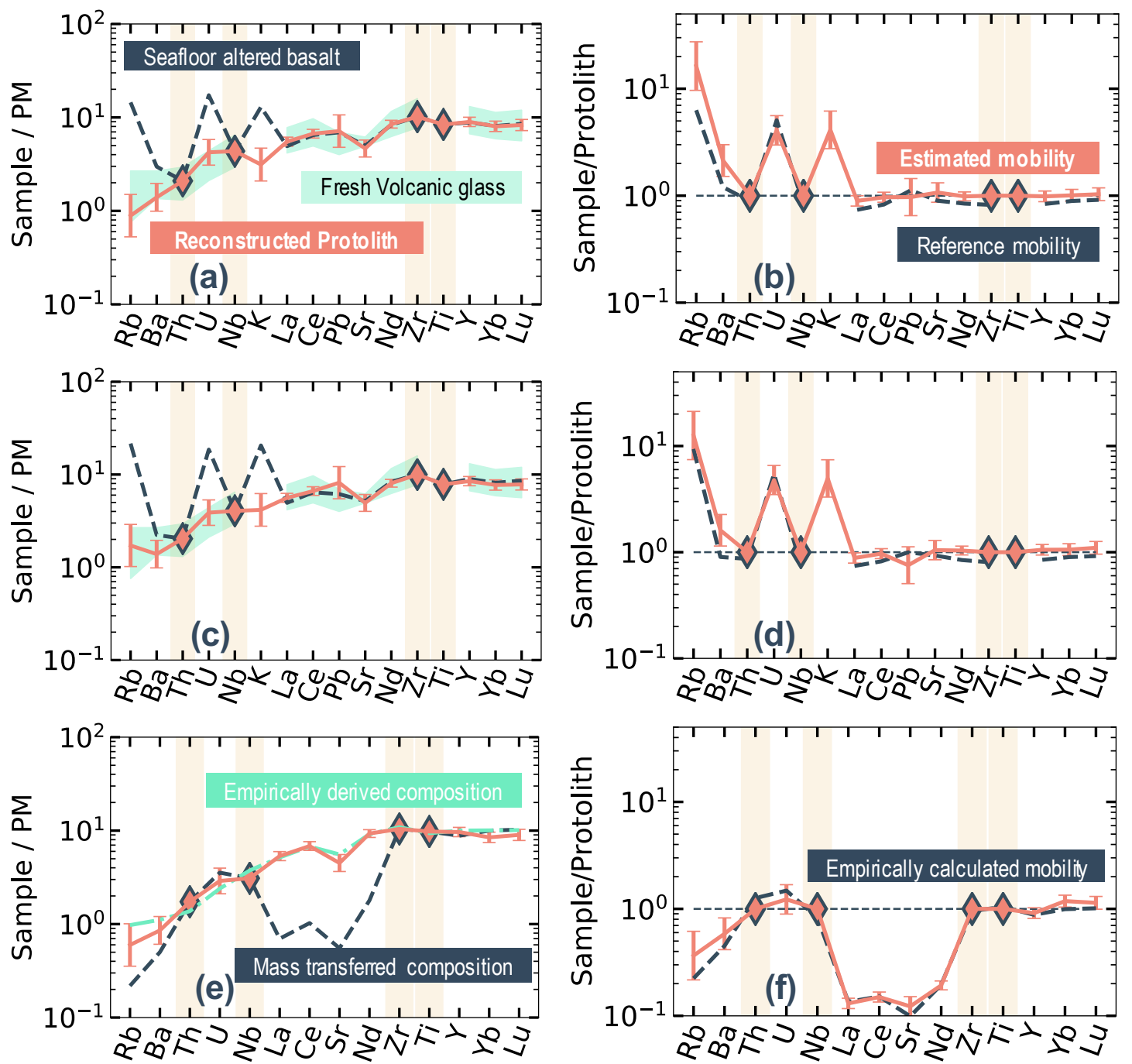

634 Figure 5. Results of the selected four-element PRM applied to seafloor altered basalt and

635 metabasalt, and calculated mass mobility. Samples for each plot are (a, b) 801-MORB110-222_ALL ${ }^{31}$, (c, d) 801_SUPER, and (e, f) Z139-655. (a, c) Primitive-mantle-

637 normalized contents of estimated protolith basalt using the PRM. Diamonds indicate 638 input data (Th, $\mathrm{Nb}, \mathrm{Zr}$, and Ti). Seafloor altered and metamorphic rock contents are shown 639 as a dashed dark-blue line, and estimated protolith basalt contents are shown as a pink 640 line. The range in protolith contents derived from fresh glass is shown as a sky-blue region.

641 (b, d) Calculated mass mobility using fresh glass composition (dashed dark-blue line) 
642 and estimated protolith (pink line). (e) Primitive-mantle-normalized contents of estimated 643 protolith basalt. Protolith compositions empirically derived ${ }^{5}$ are shown as a sky-blue line.

644 (f) Calculated mass mobility using empirically derived composition (dark-blue line) and 645 estimated protolith (pink line).

646 


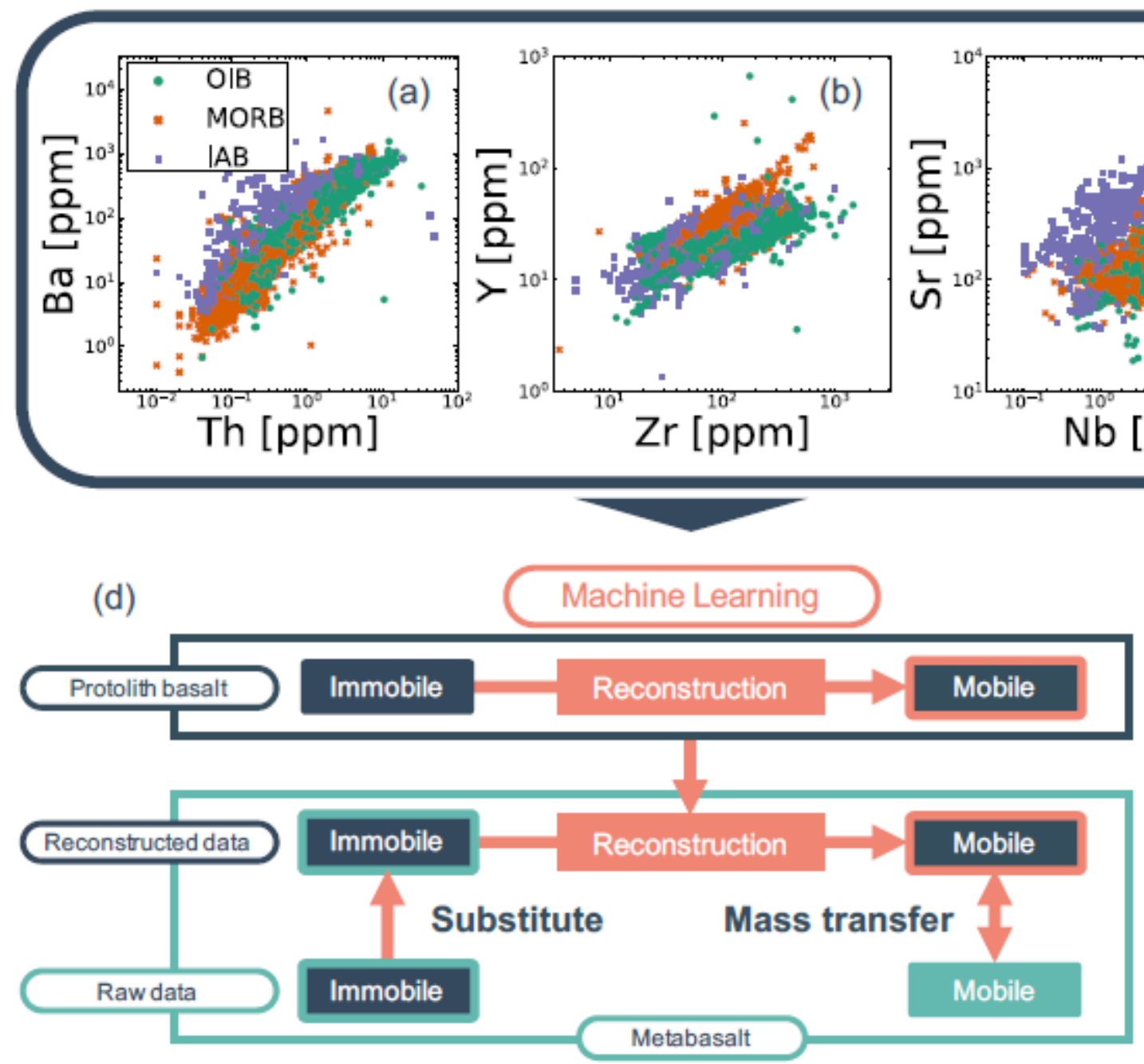

Figure 1

Distribution of the compositional dataset used in this study (compiled from the geochemical database at https://search.earthchem.org/). (a) Th and Ba, (b) Zr and Y, and (c) Nb and Sr. (d) Schematic overview of protolith reconstruction models (PRMs). Empirical models were calibrated by the protolith (basalt) compositional dataset and applied to metabasalt compositions. Assuming that the contents of immobile elements in metabasalt are identical to those in protolith basalt, these contents can be assigned as inputs and used to obtain protolith compositions. 


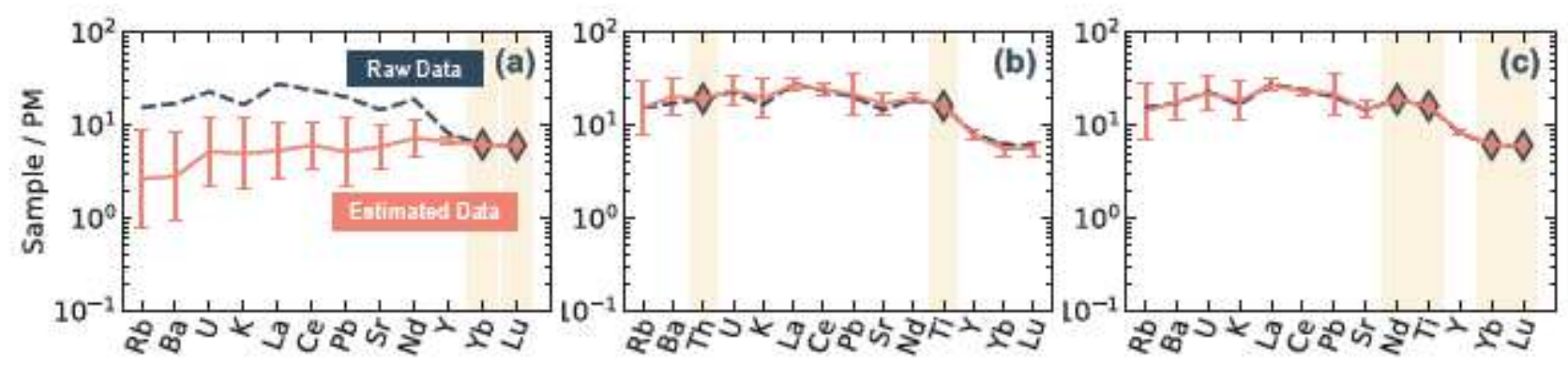

0.5

$0.4-(d)$

岁 $0.3-$

0.1 -
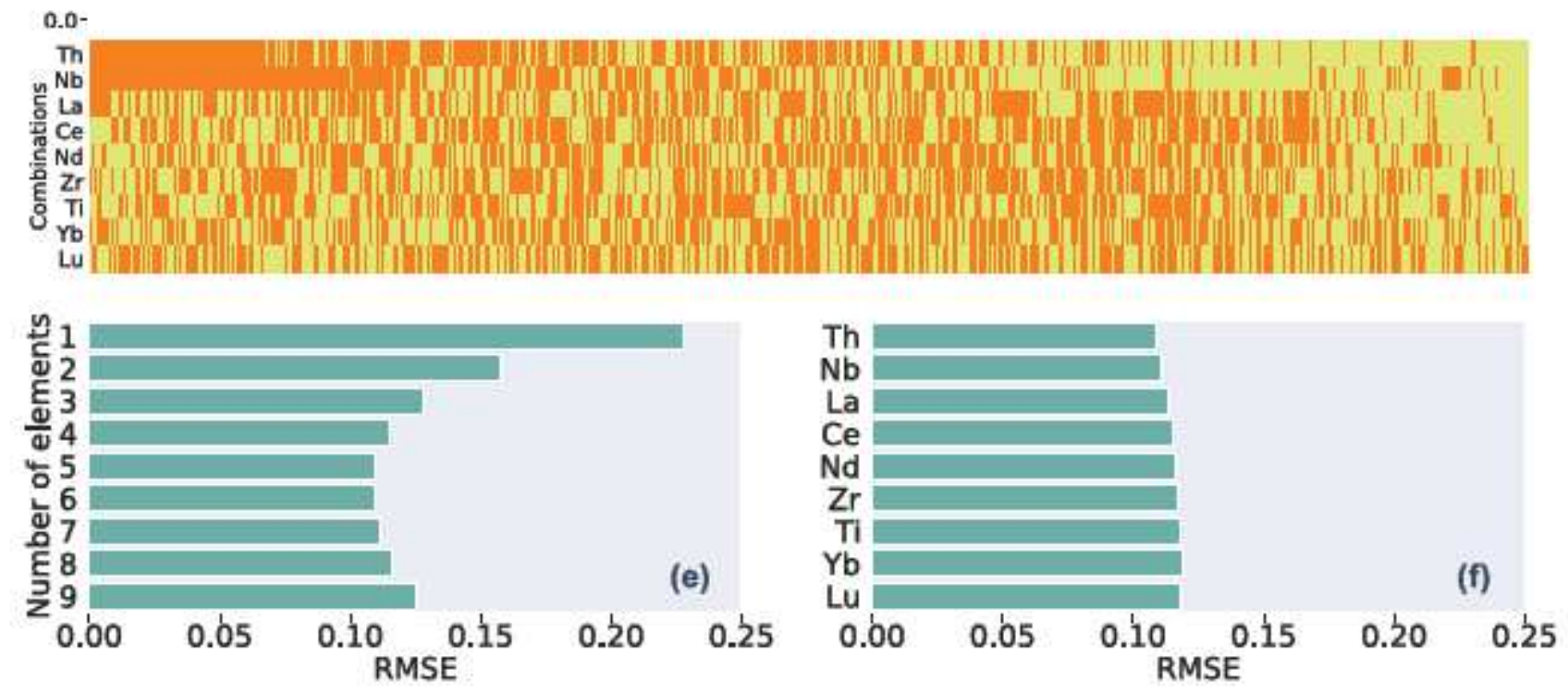

\section{Figure 2}

$(a-c)$ Estimated primitive-mantle-normalized contents of basalt. Pink diamonds indicate the input contents. Predicted data were obtained from the input contents of (a) Yb and Lu; (b) Th and Ti; and (c) $\mathrm{Nd}, \mathrm{Ti}, \mathrm{Yb}$, and Lu. Raw basalt compositional data are shown as a dashed dark-blue line, and estimated basalt compositional data are shown as a pink line. Compositions of the primitive mantle are from Sun and McDonough (1989). (d) Average RMSE scores of all output elements for each combination of input elements (511 cases), and combinations of input elements for each model shown in below. In the upper plot, the red line indicates the input combination of $\mathrm{Th}, \mathrm{Nb}, \mathrm{Zr}$, and $\mathrm{Ti}$. In the lower plot, the orange elements are used in combinations, and yellow elements are not used. (e) Average RMSE scores for all of the models using a particular number of input elements. ( $f$ ) Average of all of the models containing a particular element as an input. 

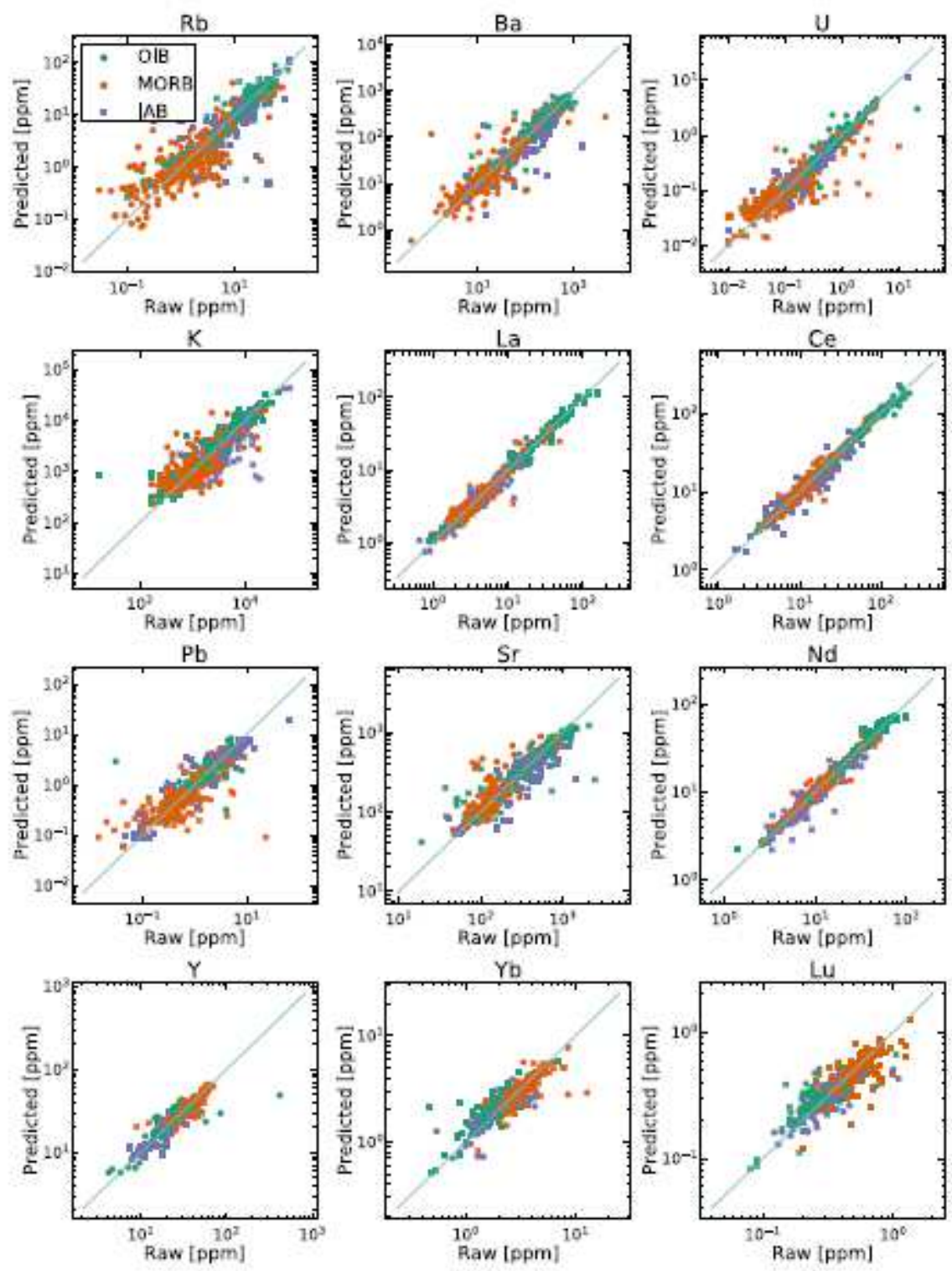

Figure 3

Scatter plots of predicted contents versus raw (measured) contents with the final PRM using Th, $\mathrm{Nb}, \mathrm{Zr}$, and Ti as input elements. The PRM was applied to test data of the basalt dataset, which covers three different tectonic settings (mid-ocean ridge basalt, ocean island basalt, and island arc basalt). 

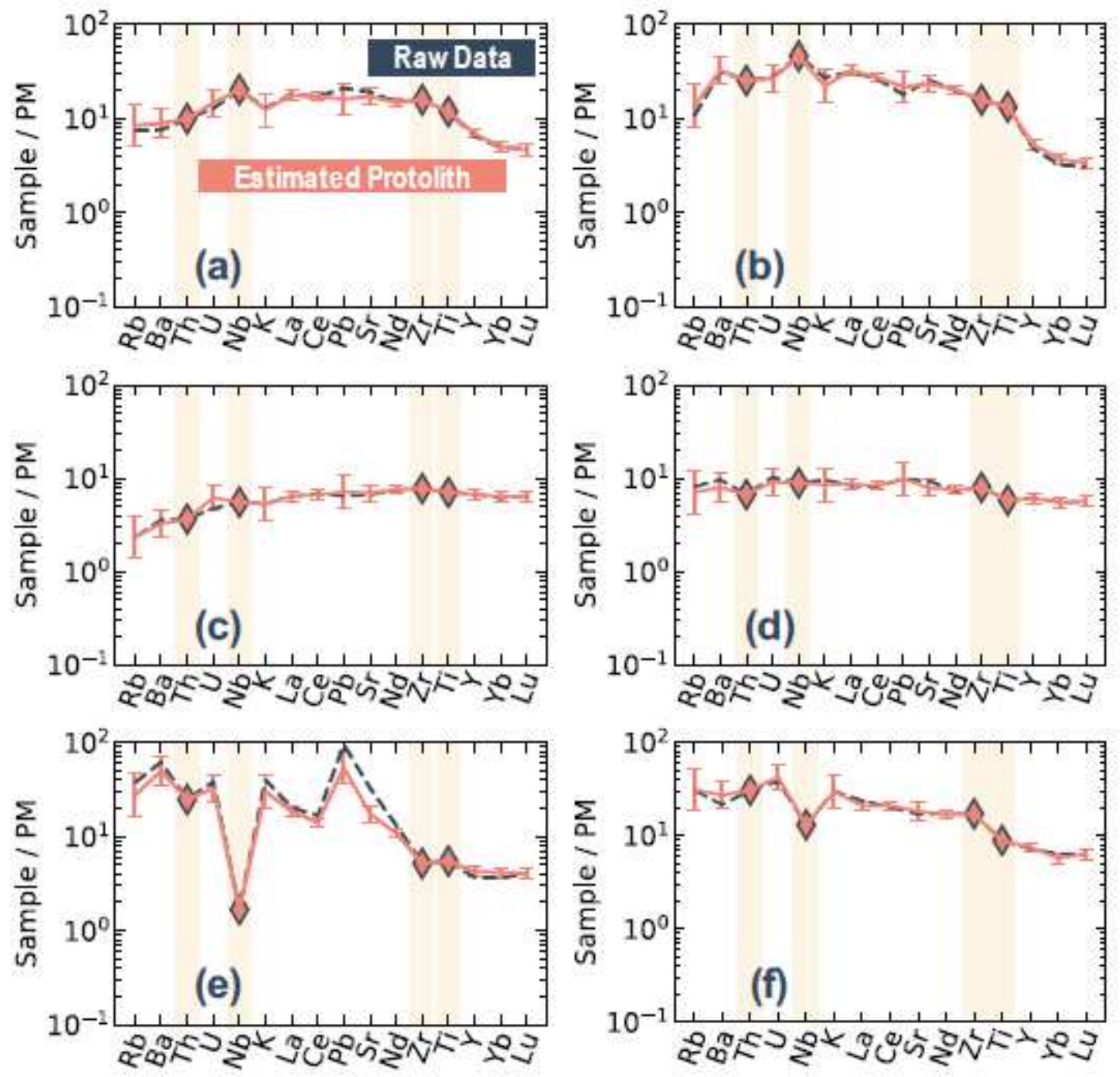

\section{Figure 4}

Primitive-mantle-normalized contents of estimated basalt using the four element PRM with $\mathrm{Th}, \mathrm{Nb}, \mathrm{Zr}$, and $\mathrm{Ti}$ as input elements. Samples for each plot are examples from $(a, b)$ OIB, (c, d) MORB, and (e, f) IAB. Diamonds indicate input data. Raw basalt compositional data are shown as a dashed dark-blue line, and estimated basalt compositional data are shown as a pink line. Compositions of the primitive mantle are from Sun and McDonough (1989). 

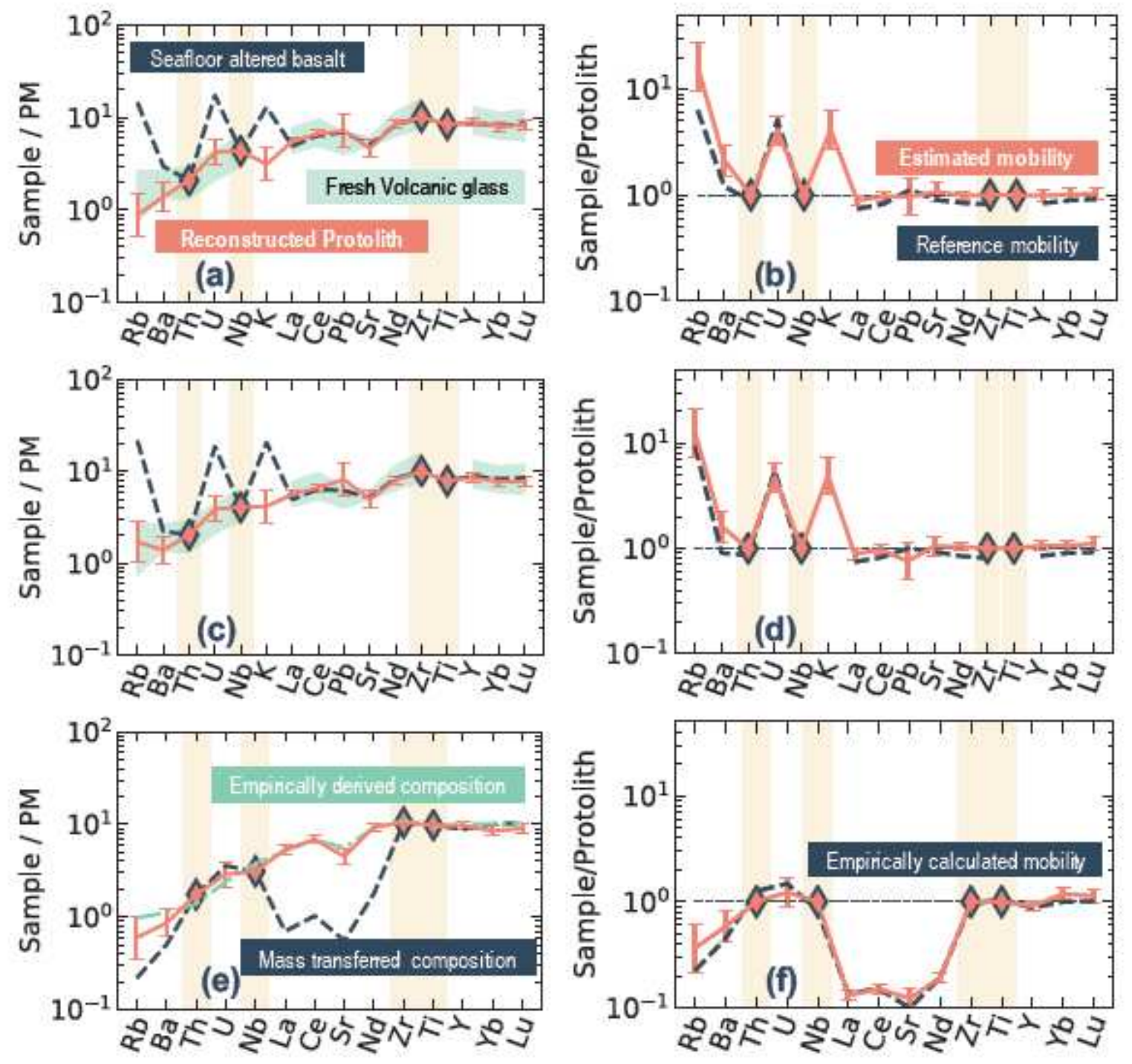

Figure 5

Results of the selected four-element PRM applied to seafloor altered basalt and metabasalt, and calculated mass mobility. Samples for each plot are (a, b) 801-MORB-110-222_ALL31, (c, d) 801_SUPER, and (e,f) Z139-65. (a, c) Primitive-mantle normalized contents of estimated protolith basalt using the PRM. Diamonds indicateinput data ( $\mathrm{Th}, \mathrm{Nb}, \mathrm{Zr}$, and Ti). Seafloor altered and metamorphic rock contents are shown as a dashed dark-blue line, and estimated protolith basalt contents are shown as a pink line. The range in protolith contents derived from fresh glass is shown as a sky-blue region. $(b, d)$ Calculated mass mobility using fresh glass composition (dashed dark-blue line) and estimated protolith (pink line). (e) Primitive-mantle-normalized $\mathbb{\|} \| \mathbb{Q}$ contents of estimated protolith basalt. Protolith compositions empirically derived 5 are shown as a sky-blue line. (f) Calculated mass mobility using empirically derived composition (dark-blue line) and estimated protolith (pink line).

\section{Supplementary Files}


This is a list of supplementary files associated with this preprint. Click to download.

- 2supplementary210526.pdf 